\title{
5.2 Entrevista a Fior Mieses, profesora de Biología del Recinto Santo Tomás de Aquino
}

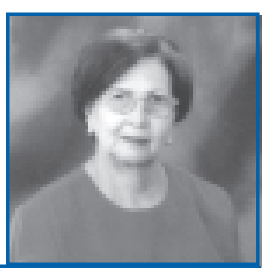

por Mary Cantisano ${ }^{1}$

Fior Mieses

\section{Resumen}

En este número del Cuaderno hemos entrevistado a una profesora cuya vocación a la docencia durante gran parte de su vida nos muestra que el magisterio es una profesión cargada de valores admirables y grandes retos que superar.

MC: Fior, usted me ha dicho que tiene toda una vida dando clases. ¿Qué significa eso?

FM: Me inicié como monitora en la Universidad Autónoma de Santo Domingo cuando fui estudiante y le tomé amor a la docencia, a enseñar a la gente. Allí tenía mis propios estudiantes, los ayudaba en el desarrollo de la parte práctica y seguí en esta carrera docente aunque, si quiero ser honesta, mi sueño era ser médico. En aquella época, los padres influían mucho en la decisión de los hijos para la carrera, especialmente en las mujeres. Mi mamá quería que yo estudiara Filosofía; sin embargo, rompí el patrón y estudié un pensum largo y extenso como era el de la Industria Farmacéutica. Ya que no me gusta vender, le tomé cariño a transmitir lo que yo sabía a los demás y en eso he pasado mi vida. Estudié, además, Biología y ahora estoy haciendo una maestría en Docencia Universitaria. Llevo 40 años siendo profesora.

MC: ¿Cómo sucede que después de tantos años en el ejercicio de la docencia, usted haga una maestría en Educación Superior?

FM: Para mí enseñar es estudiar todos los días, porque yo sé siempre lo que voy a decir, pero no sé nunca lo que un estudiante me va a preguntar. En una época donde hay tanto avance, hay muchas veces que el estudiante hace una pregunta y el profesor no tiene la respuesta. Pero esto es porque nadie tiene el conocimiento absoluto de todo lo que enseña y no porque uno ha sido descuidado en su trabajo.

MC: ¿Usted entiende que en estos momentos hay estrategias de enseñanza diferentes? ¿Usted se define como una mujer abierta a las innovaciones?

FM: Me considero no solamente abierta a las innovaciones de la enseñanza sino a los estudiantes que tengo enfrente. Por ejemplo, ayer yo daba una clase y las preguntas que me hacían no se parecían a las que escuchaba hace diez años. Tengo que entender que el estudiantado de hoy que hace esa pregunta es más abierto y no tiene los temores de antes sobre sexo, enfermedades, relaciones sexuales y muchas otras cosas sobre las que los jóvenes tienen inquietudes.

MC: Usted tiene mucho que decirnos sobre las brechas generacionales, porque cuando empezó la docencia había unas condiciones sociales, políticas y culturales que influían en la clase.

Toda persona tiene que estar acorde con el cambio de los tiempos y yo he pasado por momentos en que los estudiantes eran políticamente fogosos. Yo tenía que manejar al estudiante que era activista, que protestaba y le llamaba la atención sabiendo que su comportamiento no respondía a la realidad de la clase en sí. Ya esa fogosidad no se ve

1 Coordinadora del Centro de Desarrollo Profesoral, Pontificia Universidad Católica Madre y Maestra, Recinto Santo Tomás de Aquino, Santo Domingo. 
en los estudiantes; ahora mas bien son indiferentes a lo que está pasando en su país.

\section{MC: Los estudiantes entienden que se estudia para algo, ¿Qué creen ellos que es ese algo, para qué les sirve el conoci- miento, la educación?}

FM: El estudiante con el que comencé era más consciente de para qué estudiaba; a veces uno los ve en la universidad como si estuvieran ahí sólo porque su familia los manda. Es un número de estudiantes que habría que tomar en cuenta, porque a mí me preocupa para qué se preparan y cómo se apropian del conocimiento. Cuando yo comencé, los estudiantes iban ávidos de conocimientos, porque tenían deseo de superación. En las universidades privadas, ese deseo no es tan fuerte porque tienen otros medios de vida y superarse no es lo básico para ellos.

\section{MC: El componente} social juega su papel en términos de interés, de objetivo último de la educación. Entonces ¿Usted piensa que el docente de la educación superior ha podido reconocer la transformación del estudiantado en el transcurrir del tiempo? ¿Cómo se expresa esto?

FM: Yo creo que la satisfacción más grande que tenemos los maestros es ver que los estudiantes a quienes les hemos dado clase aparecen con frecuencia en el ámbito público. Nos hace sentir orgullosos que gente sumamente joven está tomando el control de este país. Podemos ver estudiantes que fueron exitosos como alumnos, que luego toman cargos de envergadura y quedan bien. Hay mucha gente buscando preparación, haciendo estudios fuera y dentro del país.
MC: En el Centro de Desarrollo Profesoral trabajamos con docentes $y$ vemos que la mayoría son profesionales, no docentes, que no es el caso suyo. Tenemos profesionales que dan clase porque se les reconoce su trabajo en la sociedad, pero a veces creen que porque son buenos en su área, son también capaces de enseñar.

FM: Yo pienso que en principio así comenzó la mayoría de la gente, siendo un buen profesional y por eso enseñaba. Hoy en día el buen profesional puede recurrir a ser un buen maestro. En mis tiempos de estudiante tuve maestros que eran excelentes profesionales sin ser buenos maestros y viceversa. El ser maestro implica un montón de cosas, no sólo el conocimiento, sino el manejo de la parte humana. Si te separaste de eso, nunca podrás ser un buen maestro.

MC: Los momentos actuales ameritan cambios, sin embargo, el protagonismo del maestro tradicional no lo podemos condenar pues uno ve cosas positivas que ese maestro tiene. El no avanzar con los tiempos quizás tenga que ver con la ética.

FM: El protagonismo tiene que pasar un tiempo manteniéndose. Por ejemplo, si un estudiante no puede comprar un libro de 900 pesos, el profesor tiene que ser la fuente de ese conocimiento. Si ponemos un trabajo para que consulten en la red, puede ser que todavía haya un montón de estudiantes que en su casa no tienen una computadora. Nos queda la biblioteca, pero algunos van directamente de su trabajo a la universidad, y por tanto, no pueden dedicarle muchas horas a la biblioteca. No es como el estudiante tradicional que sólo 
estudiaba; por eso, el protagonismo va a estar aún presente por muchas razones.

Con relación a la ética, tener una conducta adecuada implica transmitir unos valores. Yo no le puedo exigir a un estudiante que apague su celular si el mío está prendido. Hay que educar con el ejemplo, yo les digo a los estudiantes que pueden hacer todo lo que yo hago y decir todo lo que yo digo. Por ejemplo; hay una degradación muy grande con relación al idioma, la gente usa malas palabras las 24 horas del día. Y les digo que como yo no digo malas palabras, ellos tampoco. Ahí les estoy transmitiendo un valor. Otro ejemplo: yo hablo en un tono muy bajo y la gente habla alto; sin embargo, mis estudiantes hablan bajo. Cuando tú pasas al lado de un aula donde yo doy clase, no se siente ningún ruido. En la primera semana todo el mundo se pasa diciéndome que no me oyen, la segunda semana ya todos me oyen y hablan en el mismo tono de
La ética consiste en que yo eduque con el ejemplo, porque no les puedo exigir algo que no estoy haciendo. se ventilaron cosas que antes no salían. Eso significó un espacio de avance.

Sobre la participación pública, esto es más complejo. Todavía el maestro no tiene esa voz. Hay gente que ha sido maestro toda su vida. Su trayectoria ha sido significativa; sale en la prensa, pero no veo que es lo cotidiano. Tenemos que forjarnos nuestro espacio y hacernos oír sobre ese tipo de temas. Por ejemplo, con el caso actual de la epidemia del Dengue, la conciencia sobre la enfermedad se creó en las escuelas y los maestros tuvieron la voz cantante, porque no todo el mundo llega a un periódico. Yo creo que las cosas están cambiando.

MC: ¿Qué propondría usted del rol del docente en la etapa universitaria del ser humano?

FM: Lo más importante está en que quien está trabajando en el magisterio lo hace por un verdadero deseo de enseñar; eso prima sobre todo lo demás. En voz. La ética consiste en que yo eduque con el ejemplo, porque no les puedo exigir algo que no estoy haciendo. Los jóvenes adultos de la universidad me responden a ese método. No creo que en mi vida profesional haya tenido más de dos estudiantes que me hayan faltado al respeto. El primer día de clase les doy una serie de normativas que se deben cumplir.

\section{MC: ¿Considera usted que existen "voces docentes"? ¿Tenemos un espacio para dialogar, para presentar innovaciones? ¿Nos sentimos consul- tados, participando en reformas?}

FM: Aquí en la PUCMM sí hay espacios para reunirse, para hablar, para planificar. Estoy conforme con esta Institución, pues eso existe. Algunos docentes creamos dichos espacios, pues ahora con la unificación de los dos recintos, tuvimos una reunión con los dos Decanos que fue muy productiva; este trabajo no hay competitividad económica; estamos dando lo mejor de nosotros y dejando renglones más productivos. Después de que te enganchas de maestro, difícilmente te separas; ves gente que económicamente tiene ocupaciones muy productivas y como quiera enseñan. Pero también es cierto que hay gente que tiene que tomar otra opción porque con el deseo no se va al supermercado. Tú trabajas el día entero con gran responsabilidad, dando lo mejor de ti misma y no ganas lo que gana tu hijo, que trabaja en una empresa, fuera del mundo educativo.

\section{Cuaderno de Pedagogía Universitaria}

